\title{
The concept of sustainable development on the eve of its thirtieth anniversary: new challenges and prospects
}

\author{
Serhiy Sonko ${ }^{1}$, Olha Vasylenko ${ }^{1,{ }^{*}}$, Nataliia Shevchenko ${ }^{1}$, Ihor Hursky ${ }^{1}$, and Yana \\ Zalizniak $^{1}$ \\ ${ }^{1}$ Uman National University of Horticulture, Department of Ecology and Life Safety, 1 Institutska Str., \\ 20300 Uman, Ukraine
}

\begin{abstract}
Considering the large-scale exacerbation of the global environmental problem in spite of almost thirty-year-long implementation of the Concept of Sustainable Development, it needs further research and justification. The article offers a new vision on the theoretical foundations for the development of such indicators. Based on the concept of noosphere ecosystems developed in previous works, an attempt to qualitatively new substantiation of the goals and directions of planetary development of the entire human population is also made. Only in bringing the mechanisms of nature management closer to natural analogues do the authors see the future trend of implementing the concept of sustainable development. The aim of the article is to establish causal links between the spatial development of mankind and the achievement of a state of sustainable development. Applied implementation of the authors' theoretical ideas in reforming the administrative and territorial system is proposed.
\end{abstract}

\section{Introduction}

The concept of sustainable development (CSD) launched as a bright hope of the inhabitants of the planet for the harmonization of relations between nature and society, demands further research, primarily because of the "lameness" of many of its theoretical ideas. All these years, following the indicators of sustainable development, which are based on GDP (gross domestic product) and HDI (human development index), humanity has not achieved anything. is becoming clear that for more successful progress towards sustainable development, a new understanding of both a mechanism of exacerbating the global environmental problem [1] and options for its solution, "fixed" in qualitatively different "indicators" is needed.

Taking into consideration that the strategy of sustainable development is manifested in both state documents and in the state standards for training future ecologists [2], the time of its more detailed analysis and probably revision has come.

\footnotetext{
*Corresponding author: vsolga05@gmail.com
} 
Modern advances in materials science, information and nanotechnology have led to the fact that today there is deliberate omission of the true value of natural resources for the development of the world economy. Ostensibly, on the eve of the seventh production and technology organization, we must forget about the biosphere and natural resources and confidently follow the path of scientific concepts in the direction of increasing the world's population to 30 billion or more [3].

Since the consumption of natural resources and, consequently, the ecological state of the environment largely depends on the understanding of the ecological essence of energy relations in ecosystems, let us recall the domestic classics of physical economics.

The successors of Serhiy Podolynsky's [4] ideas believes that not the substance converted into a new quality and that contains passive atomic energy (negentropic), but the energy contained in substances - energy carriers (entropic) is accumulated; it allows to carry out this transformation in production (to melt ore in the blast furnace, to hit the anvil with a hammer or allows a car to go etc.); it goes into space, entropies, disappears irretrievably in space in huge material volumes and is not restored. It is interesting that similar ideas (regarding the reduction of the Earth's mass) are set out in the concept of the ecological footprint of mankind [5], which has been recently considered in the list of indicators of sustainable development [6].

Taking into account the large-scale exacerbation of the global environmental problem despite almost thirty years of existence of the concept of sustainable development, its viability is beginning to be questioned (already in Johannesburg in 2012). The alarming restrictive content of this concept, laid down in Rio, is beginning to disappear, and, instead, the desire to ensure "human development" is proclaimed [7].

Therefore, taking into account the clear signs of devaluation of the concept of sustainable development on the eve of its thirtieth anniversary, it is very important to study its general scientific foundations, to develop adequate for the XXI century guidelines for its further implementation. Rather, its content should include the main condition of "sustainability", stated, but not fully "deciphered" in the definition: "sustainable development is one that ensures a secure existence not only for modern but also future generations of people on Earth" [8]. And the fulfillment of this condition presupposes the desire for such mechanisms of nature management, which were peculiar to the living nature for more than 4 billion years of existence of the biosphere.

The main prerequisites for the development of domestic physical economics cannot be assessed without a retrospective analysis of economic theories. It is known that in the early stages of economic theory, the physical equivalents of labor valuation occupied a more prominent place. For example, mercantilists identified wealth with reserves of precious metals - gold and silver, and therefore the growth of the welfare of an individual country in trade interaction of several countries considered possible only through the redistribution of wealth available in these countries.

\section{Literature review}

The twentieth century demanded from society new economic concepts, which took shape in a number of areas: neoclassical, Keynesian, institutional and sociological. Following neoclassical theory has led the world economy to a number of global crises and has led today to a gradual revival of the main theoretical foundations of physical economics, well known in the history of domestic economic thought, primarily through the works of Serhiy Podolynsky [4]. In addition to S. Podolynsky, a number of researchers (V. Vernadsky, M. Rudenko, L. Larush, A. Shevchuk, T. Muranovsky, J. Tennenbaum [9]) in their works describe the energetic nature of the interaction of society and nature. 
The first systematic views that indicate the energetic nature of social wealth (after F. Quesnay) were set out in the last century by the Ukrainian thinker Serhiy Podolynsky [10]. According to S. Podolynsky [10], labor is the use of mechanical and spiritual energy accumulated in the body, which allows as a result of the labor process to increase the total amount of energy on the earth's surface. Under the accumulation of total energy on the earth's surface S. Podolynsky understood the creation of material values that people use in their further activities [10].

From the above opinions we see that being an agrarian country for Ukraine is not a shame at all (as it is sometimes presented by representatives of left-wing political forces), but it is very, very honorable. And sustainable development (a category close in content to the homeostasis of the biosphere) is most likely to be associated with agriculture. It is in it that the substance and energy relations of nature management are the closest ones to those that exist in natural ecosystems. The main hypothesis of our study is the assumption of the most complete implementation of the ideas of sustainable development through the approximation of nature management to the substance and energy mechanisms that exist in natural ecosystems. Such an approximation may be the most realistic in agriculture that is the closest sphere to the biosphere in terms of both the type of substance and energy relations and the area occupied on the planet.

The main tasks set by the authors: to substantiate scientifically the noosphere content of the concept of sustainable development; on the example of agro-ecosystems to show the spatial and temporal evolution of Homo Sapiens with the outline of future trends that would correspond to the idea of sustainable development; to revive the traditions of domestic physical economics, using its main ideas in the development of modernized indicators of sustainable development; to adapt the found indicators to the objective mechanisms of formation of agro-ecosystems and to put them into the basis of the administrative and territorial system.

\section{Methods}

The main method for obtaining the results of the study was the method of spatial analysis. It was implemented in the construction of spatial and cartographic models of the Kharkiv region for a period of more than 30 years. The technique of elementary GIS developed by the authors was also used. In particular, it was used to model the spatial structure of agroecosystems formed in the Kharkiv region, to establish zones of spatial entropy, and to attempt to "inscribe" the dynamics of agroecosystems formation in the modern administrative-territorial system.

The object of the research is the concept of sustainable development as a program document for further development of mankind.

The subject of the research is the scientific content of the concept of sustainable development.

\section{Results}

Substantiation of the ecosystem content of human activity in agriculture will take more than one page and will take a long time, which is not the main task of the authors. This justification was made in earlier publications in the form of the concept of noosphere ecosystems [1]. The main meaning of this concept is that a man in the process of noospheregenesis forms the same ecosystems as in the wild nature, but their spatial and temporal evolution differs in the main feature - a radical change in the ecotope due to changes in energy relations. 
Agro-ecosystems have a dual border, formed by natural landscapes and agricultural areas. Taking into account that the first formations are exclusively objects of natural genesis, and the second - purely anthropogenic, the modern boundaries of agro-ecosystems can be traced in space by "imposing" cartographically some boundaries on others. But while in the conditions of harvesting and primitive agriculture (5-8 thousand years ago) these boundaries almost coincided, today they demonstrate their serious differences. We managed to establish this fact on the example of the development of agro-ecosystems in Kharkiv region, just considering the period of 30 years. Comparing their spatial development in 1985 and in 2015 (Fig. 1), we see the following.

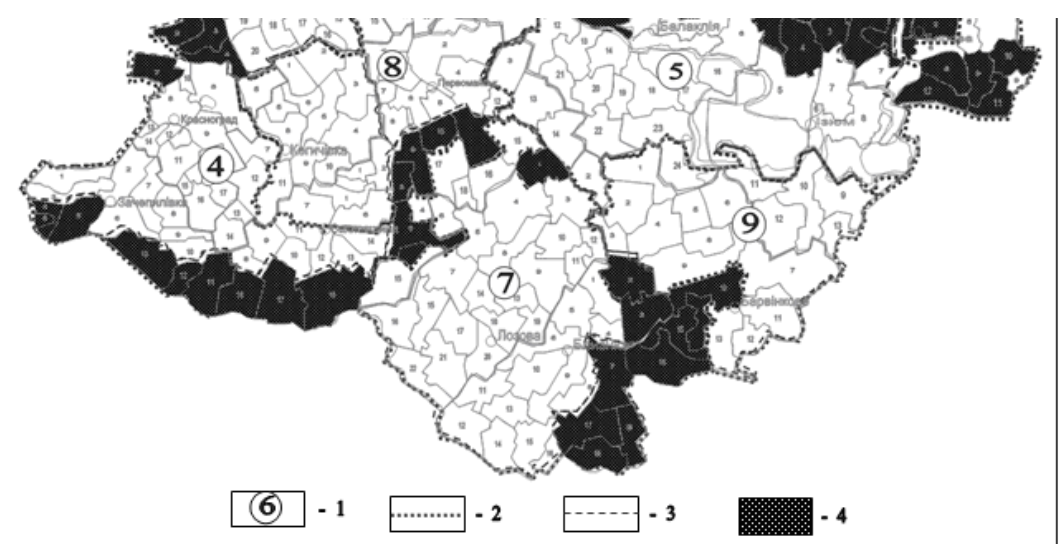

Fig. 1. Boundaries of agroecosystems that are formed in the Kharkiv region (1985, fragment): 1. numbers of agricultural areas; 2. the boundaries of agricultural areas (economic boundaries of agroecosystems); 3 . boundaries of the natural landscapes (natural boundaries of agroecosystems); 4. Areas (segments) of the space, on which "the" do not match "the natural and economic boundaries of agroecosystems.

The simplification of substance and energy relations in agro-ecosystems (mono-cultural specialization) has led to their spatial consolidation, and thus to an even greater "exit" beyond their own natural boundaries (Fig. 2).

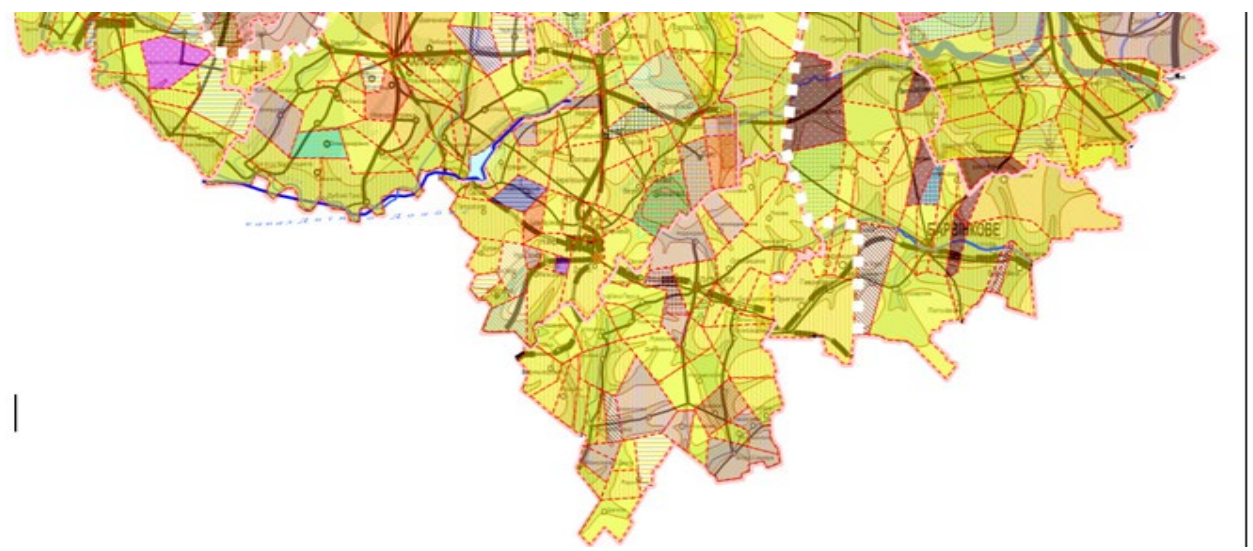

Fig.2. Modern boundaries of agroecosystems that are formed in the Kharkiv region (2015, fragment). 
The fact is that in 198511 agricultural districts were formed in Kharkiv region (Fig. 1), and then in 2015 - only 7 (Fig. 2), and, consequently, the total area of entropy stress zones will be even larger. At the same time, urbanization is being intensified alongside with depopulation of rural areas. That is, the zones of influence of urban ecosystems (expansion on the rural environment) continue to expand, causing further exacerbation of environmental problems.

According to classical ideas (S. Podolynsky) and modern ideas (V. Pysmak), such "discrepancy" leads to an increase in the level of planetary entropy, and, consequently, to information "tension", which most likely causes not only environmental but also many other" global "problems. In particular, there is a high correlation between the degree of coincidence of natural and economic boundaries of agro-ecosystems and the balance of humus in soil.

The mechanism of aggravation of a global ecological problem described above is not considered by the adherents of the concept of sustainable development: either at the dawn of its development, or now. Perhaps the comprehension of the true mechanisms of the ecological problem exacerbation will help bring nature management closer to biosphere analogues. Moreover, we must agree with the opinion that not the quotas for carbon dioxide emissions (Kyoto Protocol), but the success in supporting the mechanism of selfreproduction of natural ecosystems in specific countries should be the main guarantee of "sustainability" of nature.

As for agro-ecosystems, current estimates put carbon emissions (as the main contributor to the greenhouse effect) from world agriculture 10\% higher than the emissions from fossil fuel combustion [11]. Thus, modern agriculture is the main contributor to the greenhouse effect and this impact in conditions of deepening economic and demographic crisis will continue to grow.

A practical approach to resolving these contradictions is the revival in rural areas of such communities of people who, by the type of their spatial existence, would be close to natural ecosystems. A radical change in the spatial existence of mankind in the direction of subsistence farming will help stabilize population growth, as well as make nature management adapted to natural ecosystems [1].

The above mentioned options force us to reconsider the existing indicators of sustainable development [12] and propose those that would take into account the main requirement in nature management - its approximation to natural substance and energy mechanisms.

1. For formalizing the global environmental problem in some countries of the world the law of reducing the energy efficiency of nature formulated by Ukrainian economist Serhiy Podolynsky in the XIX century is very important. The fact is that agriculture in the developed world is characterized by very high productivity, but in terms of soil fertility and production output per 1 hectare China, for example, far exceeds the United States. In fact, we are talking about a conscious reduction of biodiversity of agro-ecosystems (through energy subvention) in developed countries, which does not contribute to sustainable development. Instead, the share of the population employed in agriculture should be at least $35-40 \%$. In this case, participation of this population directly in agricultural activities, "closed" in the specific territory by the relevant flows of substance and energy, is mandatory. Thus it is a question of establishment of obligatory quotas for a share of a subsistence economy in GDP (gross domestic product).

2. It is also necessary to introduce an indicator that would take into account the depth of the impact of developed countries on the ecosystems of other areas ("traps for space"). These can be indicators of absolute and relative consumption of biomass in carbon equivalent (the territory of the own country plus the territory of other countries from which biomass comes). Such indicators should be equated to the main constants of the biosphere. 
3. It is necessary to bring the modern spatial organization of human society to a state of sustainable development. For this purpose it is vital:

- to limit the share of urban settlements on the surface of the globe to $1 \%$ or less (which was at the beginning of the industrial era);

- to limit the influential expansion of large cities on the immediate environment to more than the average distance (in vectors) to neighboring cities of the same rank (according to the model of central places by W. Crystaller [13]);

- to limit the density of paved roads per unit of area, according to the Crystaller model "k=4";

- not to exceed the share of fodder arable land by more than $15 \%$.

In the given authors' indicators of sustainable development the spatial content of human nature-transforming activity is mainly reflected. In fact, such an approach has a right to exist also for the reason that the territorial organization of human activity hostile to natural ecosystems gradually, year after year, slowly but persistently distorts the natural mechanisms of self-regulation [14]. In fact, any reform of the administrative and territorial system must take into account the objective mechanisms of self-organization of the regions, which should be based on the ideas of the noosphere ecology [1].

Modeling the contemporary development of agro-ecosystems as primary spatial units of noospheregenesis (Fig. 1, 2) allowed to assess the level of "sustainability" of the modern administrative and territorial structure of Kharkiv region. According to the new administrative and territorial reform on the territory of the region there are 7 spatial units, which by their significance perform the functions of the former administrative districts (Fig. 3).

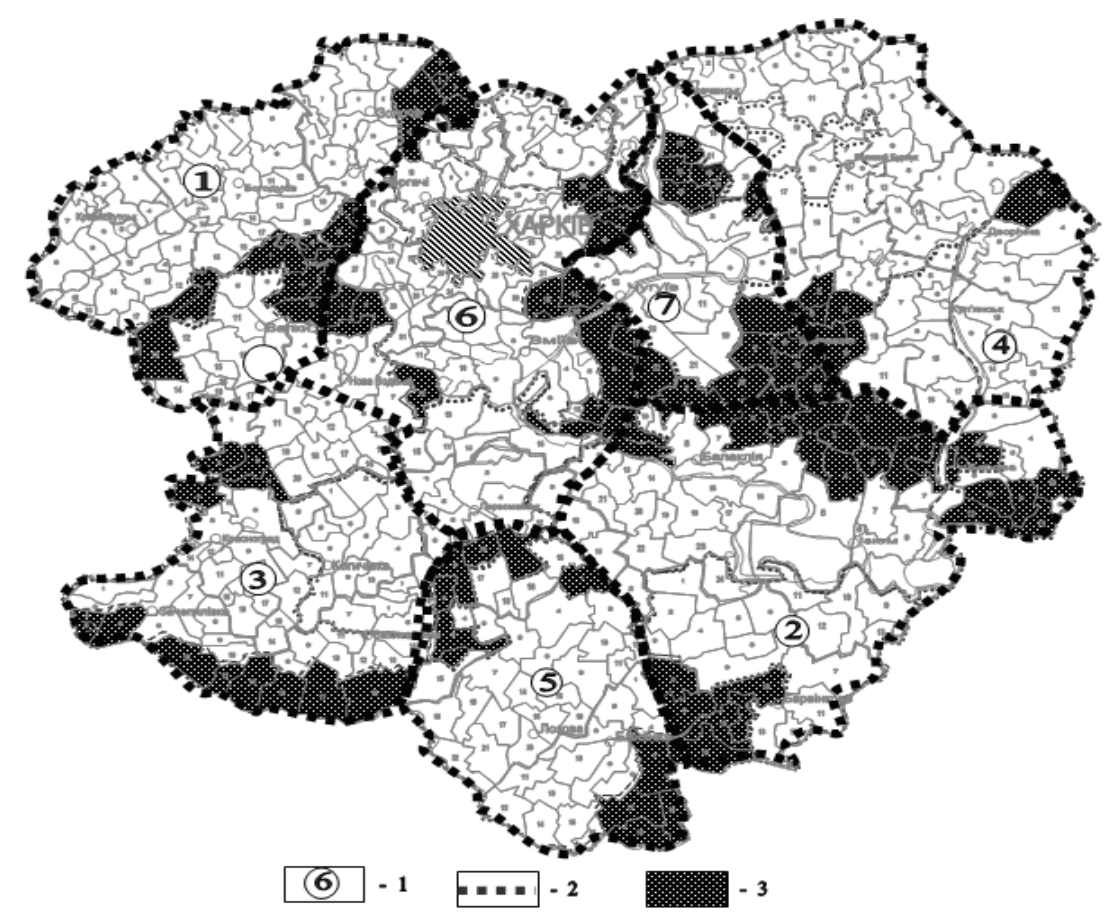

Fig. 3. Formation of zones of entropy tension in the rural administrative areas: 1 . Numbers of the rural administrative areas (1 - Bogoduhiv; 2 - Izjum; 3 - Krasnograd; 4 - Kupjansk; 5 - Lozova; 6 Harkiv; 7 - Chugujiv). 2. The boundaries of the rural administrative areas; 3 . Areas (segments) of the space entropy pressing. 
Cartographic overlapping of the boundaries of these areas on the map, which marked the zones of entropy stress, allowed to perform the following analysis:

- The largest zones of entropic stress are observed on the periphery of almost every new administrative district, which logically explains the growing spatial discomfort of the population due to limited access to administrative services because of the consolidation of districts (previously there were 26 of them) and, consequently, increasing distance.

- As modern administrative districts cover the countryside, the importance is paid to the fact that the nuclei of agro-ecosystems located within the districts are almost unchanged over time (based on the information of year 1985) and for a long time continue to play the role of spatial "condensation nuclei".

- Approaching the "sustainability" of nature management is possible on conditions of decrease of zones of entropic stress due to the increase of the number of districts to 10-12 (according to the number of relict nuclei of agro-ecosystems).

\section{Conclusions}

In the process of noospheregenesis, Homo sapiens has formed its own, no less natural, ecosystem, that is agro-ecosystem, in which producers, consumers and reducers are spatially separated, which is most likely one of the causes of exacerbation of the global environmental problem.

Probably, following the principle of Le Chatelier [14] (or the principle of compensation), we should expect a feedback from the biosphere to the expansion of Homo sapiens. To prevent it, any administrative and territorial division must be "inscribed" in the spatial and temporal dynamics of agro-ecosystems. That is why, considering the forthcoming land reform, it is proposed to do the following:

- To return the interest in working on the land to people in rural areas, finally agreeing that this land is a special space in which the rural community plays the role of an essential component of the natural ecosystem.

- In every way to promote the development of subsistence farming and bring its share in the structure of GDP to $35-40 \%$.

- Gradually to weaken the role of cities as social entities in the spatial organization of society.

- To reform the economic and, above all, financial system of the country in accordance with the concept of "energy money", proposed in the late nineteenth century by Ukrainian naturalist and economist Serhiy Podolynsky.

The authors' approach to the allocation of the primary spatial units in the noosphere organization of society will help to avoid subjectivism in the allocation and formation of united territorial communities, which is fully consistent with the main slogan of the concept of sustainable development: "Think globally, act locally!" In the near future the authors are planning to study the conformity of the administrative and territorial structure to spatial dynamics of agro-ecosystems, taking into account the offered indicators of sustainable development.

\section{References}

1. Sonko, S. (2019). Man in Noosphere: Evolution and Further Development. Philosophy and Cosmology, 22, 51-75. https://doi.org/10.29202/phil-cosm/22/5

2. Ministry of Education and Science of Ukraine. (2018). Order № 1066 of 04.10.18 «On approval of the standard of higher education in the specialty 101 «Ecology» for the second (masters) level of higher education». https://mon.gov.ua 
3. Korsak, K. V. (2013). Nootechnologies and nooecology - means of transforming the dream of sustainable development in the reality of noosociety. Man and the environment. Problems of neoecology, 1-2, 7-13. http://nbuv.gov.ua/UJRN/Ltd_2013_1-2_3

4. Podolinsky, S. (1883). Menschliche Arbeit UH d die Einheit der Kraft. Die Neue Zeit, $9,413-424$.

5. Lin, D., Hanscom, L., Murthy, A., Galli, A., Evans, M., Neill, E., Mancini, MS., Martindill, J., Medouar, F-Z., Huang, S., Wackernagel, M. (2018). «Ecological Footprint Accounting for Countries: Updates and Results of the National Footprint Accounts, 2012-2018». Resources, 7 (3), 58. https://doi.org/10.3390/resources7030058

6. Marushevskyi, G. (2015). Sustainable development indicators: Ukraine's position in international rankings. Investytsiyi: praktyka ta dosvid, 20, 141-146. http://www.investplan.com.ua/?op=1\&z=4680\&i=29

7. Khvesyk, M., Bystryakov, I. (2012). Paradigmatic view on the concept of sustainable development of Ukraine. Economy of Ukraine, 6, 4-12. http://nbuv.gov.ua/UJRN/EkUk_2012_6_2

8. Holden, E., Linnerud, K., Banister, D. (2014). Sustainable development: Our Common Future revisited. Global Environmental Change, 26, 130-139. https://doi.org/10.1016/j.gloenvcha.2014.04.006

9. Vorobyova, L. V. (2016). Ukrainian school of physical economy in the world economic space. Modern economic theories: history, methodology and prospects: a collection of materials of the Ukrainian round table, 131-134.

10. Podolinsky, S. (1880). Human labor and its relationship to the distribution of energy. Word, 4/5, 135-211.

11. Tubiello, F. N., Salvatore, M., Rossi, S., Ferrara, A., Fitton, N., \& Smith, P. (2013). The FAOSTAT database of greenhouse gas emissions from agriculture. Environmental Research Letters, 8(1), 015009. https://doi.org/10.1088/1748-9326/8/1/015009

12. Pyrikov, O. V. (2013). Indicators and sistem of sustainable development: theory and practice. Efficient economy, 11. http://www.economy.nayka.com.ua/?op=1\&z=4026

13. Dmitriev, R. V. (2019). Metrics of urban settlement systems in terms of the central place theory: constancy vs variability. Geographical bulletin, 2 (49), 24-34. https://doi:10.17072/2079-7877-2019-2-24-34

14. Smith, W.R. (2020). A precise, simple and general Basic Le Châtelier Principle based on elementary calculus: What Le Châtelier had in mind?. J Math Chem, 58, 1548-1570. https://doi.org/10.1007/s10910-020-01140-3 